\title{
Poliovirus Excretion among Persons with Primary Immune Deficiency Disorders: Summary of Data from Enhanced Poliovirus Surveillance in Egypt, 2011-2014
}

Zeinab A El-Sayed ${ }^{1}$, Ondrej Mach ${ }^{2}$, Elham M Hossny ${ }^{1}$, Nermeen M Galal ${ }^{3}$, Ihab El-Sawy ${ }^{4}$, Aisha Elmarsafy ${ }^{3}$, Shereen M Reda ${ }^{1}$, Ibrahim Moussa ${ }^{5}$, Mohamad A Sibak $^{5}$, Laila Bassiouni ${ }^{6}$, Eman Nasr ${ }^{6}$, Humayun Asghar ${ }^{7}$, Cara C Burns ${ }^{8}$, Qi Chen ${ }^{8}$, M. Steven Oberste ${ }^{8}$ and Roland W. Sutter ${ }^{2}$

${ }^{1}$ Pediatric Allergy and Immunology Unit, Children's Hospital, Ain Shams University, Cairo, Egypt

${ }^{2}$ World Health Organization, Geneva, Switzerland

${ }^{3}$ Pediatric Department, Cairo University, Cairo, Egypt

${ }^{4}$ Pediatric Respiratory Allergy and Immunology Unit, Alexandria University, Egypt

${ }^{5}$ EPI- Ministry of Health, Egypt

${ }^{6}$ VACSERA - Regional Reference Polio Network Laboratory, Egypt

${ }^{7}$ World Health Organization, Eastern Mediterranean Region, Ciaro, Egypt

${ }^{8}$ Division of Viral Diseases, Centers for Disease Control and Prevention, Atlanta, USA

"Corresponding Author: Ondrej Mach, World Health Organization, Avenue Appia 20, CH-1211, Genève 27 Suisse, Switzerland, Tel: 0041227911863; Fax: 0041227911571; E-mail: macho@who.int

Received date: Jun 17, 2016; Accepted date: Jul 25, 2016; Publication date: Jul 28, 2016

Copyright: (c) 2016 El-Sayed ZA, et al. This is an open-access article distributed under the terms of the Creative Commons Attribution License, which permits unrestricted use, distribution, and reproduction in any medium, provided the original author and source are credited.

\section{Abstract}

Background: If exposed to oral poliovirus vaccine (OPV), persons with primary immune deficiency disorders (PID) are at increased risk of paralytic poliomyelitis; and can chronically excrete poliovirus. However, the risk of excretion of vaccine derived poliovirus among immunodeficient persons (iVDPV) is not well characterized. We present summary of data from poliovirus surveillance project among PID patients collected between 2011 and 2014 from 11 Egyptian Governorates.

Methods: Stool was tested for polioviruses in suspected or confirmed PID children regardless of whether Acute Flaccid Paralysis (AFP) was present or not. Those excreting poliovirus were followed until three consecutive negative stool samples were obtained.

Results: There were 122 patients with suspected or confirmed PID identified; 13/122 (11\%) excreted poliovirus; of these, 6 excreted iVDPVs, the remaining 7 excreted Sabin virus. The duration of iVDPV excretion ranged from 1 to 21 months. AFP was detected in $3 / 6(50 \%)$ of those excreting iVDPVs. All iVDPV excretors had history of receiving OPV.

Conclusions: Chronic poliovirus excretion in PID patients is rare, however, poliovirus eradication requires removal of all polioviruses from circulation; and because PID individuals are not necessarily paralyzed they might be missed by current poliovirus surveillance based on detection of AFP. To achieve poliovirus eradication, surveillance for polioviruses among PID patients should be routinely conducted in all countries, and poliovirus antiviral therapy must be made available for those with chronic excretion.

Keywords: Poliovirus excretion; Primary immune deficiency; Paccine-derived polioviruses; OPV

\section{Introduction}

The global effort to eradicate poliomyelitis owes much of its success to the effective use of the oral poliovirus vaccine (OPV) in routine immunization and supplemental immunization activities (SIAs). OPV, in contrast to the injectable inactivated poliovirus vaccine (IPV), contains live attenuated polioviruses and offers the advantage of easy oral administration appropriate for volunteer use [1]. However, in rare circumstances, OPV polioviruses can cause vaccine-associated paralytic poliomyelitis (VAPP) [2]. In addition, through prolonged replication in a single immunodeficient host or serial transmission in an under-vaccinated community these attenuated polioviruses can evolve and regain the neurovirulence and transmission characteristics of wild poliovirus [3,4]. These vaccine-derived polioviruses (VDPVs) are capable of circulating and causing paralytic poliomyelitis with an identical clinical presentation as caused by wild poliovirus. VDPVs establishing community circulation are referred to as circulating vaccine-derived polioviruses (cVDPVs) [4].

Primary immunodeficiency disorders (PIDs) represent a large array of immune system disorders jointly characterized by impaired function of the immune system $[5,6]$. Individuals with PID, especially those disorders affecting the B-cell system, are at highest risk for developing VAPP [7]. In addition, prolonged intestinal poliovirus replication in PID patients may lead to development of VDPVs referred to as 
Citation: El-Sayed ZA, Mach O, Hossny EM, Galal NM, El-Sawy I, et al. (2016) Poliovirus Excretion among Persons with Primary Immune Deficiency Disorders: Summary of Data from Enhanced Poliovirus Surveillance in Egypt, 2011-2014. J Vaccines Vaccin 7: 331. doi:

Page 2 of 6

immunodeficiency-related vaccine-derived polioviruses (iVDPVs) $[8,9]$.

Any VDPV is considered a significant threat to polio eradication because it can be reintroduced into the general population and cause outbreaks of paralytic poliomyelitis. Over a dozen such outbreaks have been recorded throughout the world in the last ten years [10]. The largest recorded cVDPV outbreak in Nigeria caused paralysis in 385 predominantly young children between 2005 and 2012 [11-14].

To date, the only documented occurrence of iVDPV community circulation was in the USA, in an Amish community with low immunization coverage in $2005[15,16]$. This iVDPV circulation did not result in any case of paralytic disease.

Recognizing the risk that iVDPVs pose to global poliovirus eradication, the World Health Organization (WHO) maintains a registry of known iVDPV excretors and is promoting global surveillance for iVDPVs. Between 1962 and 2015, 107 individuals with long-term iVDPV excretion have been included in this registry [WHO data as of February 1, 2016]. The vast majority of these cases were identified from upper or middle-income countries and have either spontaneously stopped shedding poliovirus or died. In seven cases, iVDPV excretion was reported to last for over five years. In one reported case, an individual has been excreting iVDPV for over 28 years [17]. All of the chronic excretors included in the registry suffered from common variable immune deficiency (CVID) and therefore CVID patients represent the most important reservoir of potential long-term poliovirus excretors. To protect PID patients with prolonged poliovirus excretion against development of paralysis and to prevent community spread, polio antiviral products are being developed, with a goal for drug approval in 2017 [18,19]. However, surveillance to detect PID patients excreting iVDPVs remains limited, particularly for those PID patients without paralytic manifestation.

Acute flaccid paralysis (AFP) surveillance is a cornerstone of surveillance for polioviruses worldwide and is well established in most countries. AFP surveillance relies on timely identification of paralyzed patients and stool testing for polioviruses [20]. Some reports of iVDPV excretion in paralyzed PID patients diagnosed through AFP surveillance are available; however, little data exist on those PID patients who had not been paralyzed and therefore had not been captured through AFP surveillance [21]. These individuals are the potentially missed cases of poliovirus excretion that, if not identified and treated, may pose risk to poliovirus eradication.

Because limited data exist on the prevalence and outcome of prolonged or chronic poliovirus excretors in middle and lower income countries, WHO initiated a study series with the objective to better describe epidemiology of iVDPV and to estimate the risk of iVDPV excretion among PID patients [22]. In this report, we summarized data collected between January 2011 and December 2014 from the iVDPV excretor surveillance project in Egypt, one of the countries that participated in the study series. The objectives of this surveillance project was to estimate the prevalence of iVDPV excretion among persons diagnosed with PID; to establish a pilot national iVDPV surveillance project, integrated with AFP surveillance, that could serve as a model for other countries to implement as a means of minimizing the global risk of iVDPVs in the post-OPV cessation era; and to build capacity to monitor and respond to iVDPVs. During the period covered by this report, Egypt has used only OPV in its routine immunization program, with a plan to add IPV in 2016.

\section{Methods}

The surveillance for iVDPV was established in participating health facilities, initially in 3 governorates of Egypt: Cairo, Giza and Alexandria. In 2013 it expanded to involve 8 additional governorates (Gharbiya, Kafr El Sheikh, Dakahliya, Qalioubiya, Sharkiya, Port Saeid, Ismailiya, Beheira), which comprise approximately 54/87 million (62\%) of the total population of Egypt. As part of this project, 960 physicians and other AFP surveillance personnel were trained on how to recognize PID patients and implement the surveillance for iVDPV.

Persons below 18 years of age who were diagnosed with either suspected or confirmed PIDs were identified as potential iVDPV excretors; and their stools were tested for the presence of poliovirus using standard poliovirus detection methodology used in the Global Polio Laboratory Network $[23,24]$. Two stool samples were collected from each patient; the collection of the second sample was performed 24 hours after the collection of the first sample. In addition, one blood sample was collected for complete blood counts (CBC) and quantitative measurement of immune globulins (QIGs).

A broad definition was used for suspected PID patients based on increased susceptibility to infections. Patients who presented at participated health facilities with at least one of the 10 warning signs for PID, which were developed by the Jeffrey Modell Foundation, were classified as suspected PIDs [25]. A confirmed PID diagnosis, for the purpose of this project, was based on CBC, QIG values, and clinical assessment. Definitive diagnosis, treatment and follow-up of patients with PID was carried out in the three main focal pediatric immunology centers (at Ain Shams University, Cairo University and Alexandria University) and required further investigations such as CD markers, phagocytic functions, imaging studies, and molecular diagnosis, as necessary.

If stool sample was positive for VDPV or Sabin-like virus (SL), it was repeated monthly until either the sample was no longer positive on three consecutive occasions, or the subject was lost to follow-up or passed away.

Partial genome sequences were determined for all detected polioviruses. VDPV was defined as poliovirus isolates with at least 10 nucleotide differences in the VP1 region from Sabin vaccine strain for serotypes 1 and 3, or 6 nucleotide differences for serotype 2 [4]. SL virus was defined as virus related to Sabin vaccine virus with $0-9$ nucleotide substitutions ( $0-5$ for type 2 ).

The WHO polio reference laboratory at VACSERA, Cairo, carried out virus isolation from the stool samples and the Polio and Picornavirus Laboratory, Centers for Disease Control and Prevention, Atlanta, USA sequenced the polioviruses found in the stool samples.

\section{Results}

Between January 2011 and December 2014, 122 patients were identified as having suspected (18/122) or confirmed (104/122) PID. They were predominantly male $(81 \%)$ and less than 5 years of age (67\%). In those with confirmed PID diagnoses (104/122, 85\%), combined immune deficiency (CID) was the most predominant (29/104, 28\%); CVID was diagnosed in 8/104 (8\%) (Table 1).

Among the PID patients, $7 / 122(6 \%)$ excreted SL poliovirus and 6/122 (5\%) excreted iVDPVs (one excreted iVDVP1, four excreted iVDPV2, and one excreted iVDPV3). 
Citation: El-Sayed ZA, Mach O, Hossny EM, Galal NM, El-Sawy I, et al. (2016) Poliovirus Excretion among Persons with Primary Immune Deficiency Disorders: Summary of Data from Enhanced Poliovirus Surveillance in Egypt, 2011-2014. J Vaccines Vaccin 7: 331. doi: $10.4172 / 2157-7560.1000331$

Page 3 of 6

\begin{tabular}{|c|c|c|}
\hline \multicolumn{2}{|l|}{ Characteristic } & \multirow{2}{*}{$\begin{array}{l}\mathrm{n} / \mathrm{N}(\%) \mathrm{N}=122 \\
81 / 122(64 \%)\end{array}$} \\
\hline Gender & Male & \\
\hline \multirow[t]{5}{*}{ Age $^{*}$} & $0-1$ year & $32 / 97$ (33\%) \\
\hline & $1-5$ years & $33 / 97(34 \%)$ \\
\hline & $5-15$ years & $30 / 97(31 \%)$ \\
\hline & $15-18$ years & $2 / 97(2 \%)$ \\
\hline & Confirmed & 104/122 (85\%) \\
\hline \multirow[t]{5}{*}{ PID Diagnosis } & CID (including SCID) & 29/104 (28\%) \\
\hline & CVID/ Hypogammaglobulinemia & 22/104 (21\%) \\
\hline & Agammaglobulinemia & 18/104 (17\%) \\
\hline & Other PID & $35 / 104(34 \%)$ \\
\hline & Suspected PID & 18/122 (15\%) \\
\hline
\end{tabular}

\begin{tabular}{|c|c|c|}
\hline Received IVIG ${ }^{*}$ & Yes & $51 / 92(55 \%)$ \\
\hline
\end{tabular}

Table 1: Demographic characteristics of detected PID patients and their diagnosis.

The patient who excreted iVDPV 3 had had SL3 detected in the first collected stool sample; however, the SL3 evolved into iVDPV3 in the sample taken one year later and remained detectable in another three monthly samples; the three subsequent samples were negative. The patient underwent stem cell transplantation and, in the end of 2015, was surviving with mild residual paralysis (Table 2, patient 5). This patient has a twin sibling, also diagnosed with PID, who was found to excrete iVDPV2 (Table 2, patient 2). In addition to poliovirus excretors, we found 20/122 (16\%) patients excreting non-polio enteroviruses (NPEV). The NPEVs were not characterized further.

\begin{tabular}{|c|c|c|c|c|c|c|c|c|c|c|c|c|c|}
\hline & \multirow[t]{2}{*}{ Case \# } & \multirow[t]{2}{*}{$\begin{array}{l}\text { Initial } \\
\text { Sampl } \\
\text { e Type }\end{array}$} & \multirow[t]{2}{*}{$\begin{array}{l}\text { Initial } \\
\text { Sample } \\
\text { (Date) }\end{array}$} & \multirow{2}{*}{$\begin{array}{l}\text { Nucleotide } \\
\text { changes } \\
\text { from Sabin } \\
\text { poliovirus of } \\
\text { initial } \\
\text { sample }\end{array}$} & \multirow[t]{2}{*}{$\begin{array}{l}\text { Final } \\
\text { positiv } \\
\text { e } \\
\text { Sampl } \\
\text { e Type }\end{array}$} & \multirow{2}{*}{$\begin{array}{l}\text { Nucleotide } \\
\text { changes } \\
\text { from Sabin } \\
\text { poliovirus of } \\
\text { final } \\
\text { positive } \\
\text { sample }\end{array}$} & \multirow[t]{2}{*}{$\begin{array}{l}\text { First } \\
\text { negative } \\
\text { Sample } \\
\text { (Date) }\end{array}$} & \multirow{2}{*}{$\begin{array}{l}\begin{array}{l}\text { Number } \\
\text { of } \\
\text { Samples } \\
\text { Obtained }\end{array} \\
\text { (two stool } \\
\text { samples } \\
\text { obtained } \\
\text { each time) }\end{array}$} & \multirow[t]{2}{*}{$\begin{array}{l}\text { Duration } \\
\text { of } \\
\text { sheddin } \\
\mathrm{g} \\
\text { (weeks) }\end{array}$} & \multirow[t]{2}{*}{$\begin{array}{l}\text { Last } \\
\text { OPV } \\
\text { Dose } \\
\text { (Date) }\end{array}$} & \multirow[t]{2}{*}{$\begin{array}{l}\text { PID } \\
\text { Type }\end{array}$} & \multirow[t]{2}{*}{$\begin{array}{l}\text { Age at PID } \\
\text { Diagnosis }\end{array}$} & \multirow[t]{2}{*}{$\begin{array}{l}\text { AFP } \\
\text { (yes/no) }\end{array}$} \\
\hline & & & & & & & & & & & & & \\
\hline \multirow{7}{*}{$\begin{array}{l}\text { iVDPV } \\
\text { Excret } \\
\text { ors }\end{array}$} & \multirow[t]{2}{*}{1} & \multirow[t]{2}{*}{ iVDPV1 } & \multirow{2}{*}{$\begin{array}{l}05-03-20 \\
11\end{array}$} & \multirow[t]{2}{*}{19} & \multirow[t]{2}{*}{ iVDPV1 } & \multirow[t]{2}{*}{19} & \multirow{2}{*}{$\begin{array}{l}06-08-201 \\
2\end{array}$} & \multirow[t]{2}{*}{6} & \multirow[t]{2}{*}{7} & \multirow[t]{2}{*}{ Mar-11 } & Agamma & \multirow[t]{2}{*}{$21 \mathrm{mo}$} & \multirow[t]{2}{*}{ yes } \\
\hline & & & & & & & & & & & $\begin{array}{l}\text { globuline } \\
\text { mia }\end{array}$ & & \\
\hline & 2 & iVPDV2 & $\begin{array}{l}06-03-20 \\
11\end{array}$ & 13 & - & - & - & 1 & 13 & Feb-11 & SCID & $9 \mathrm{mo}$ & no \\
\hline & 3 & iVDPV2 & $\begin{array}{l}07-03-20 \\
12\end{array}$ & 11 & - & - & - & 1 & 8 & May-12 & SCID & $5 \mathrm{mo}$ & no \\
\hline & 4 & iVDPV2 & $\begin{array}{l}12-04-20 \\
12\end{array}$ & 10 & & - & - & 1 & 10 & Sep-12 & CID & $6 \mathrm{mo}$ & yes \\
\hline & 5 & SL3 & $\begin{array}{l}06-08-20 \\
11\end{array}$ & - & iVDPV3 & 48 & $\begin{array}{l}12-08-201 \\
2\end{array}$ & 8 & 82 & Feb-11 & SCID & $9 \mathrm{mo}$ & yes \\
\hline & 6 & iVDPV2 & $\begin{array}{l}12 / 21 / 20 \\
13\end{array}$ & 11 & iVDPV2 & 11 & -- & 2 & 12 & Nov-13 & SCID & $6 \mathrm{mo}$ & no \\
\hline \multirow{6}{*}{$\begin{array}{l}\text { Sabin } \\
\text { Virus } \\
\text { Excret } \\
\text { ors }\end{array}$} & 7 & SL1 & $\begin{array}{l}3 / 15 / 201 \\
3\end{array}$ & - & - & - & 8/20/2013 & 2 & - & Jan-13 & CVID & $67 \mathrm{mo}$ & no \\
\hline & 8 & SL1 & $\begin{array}{l}01-06-20 \\
14\end{array}$ & - & - & - & $7 / 22 / 2014$ & 2 & - & Apr-14 & CID & $6 \mathrm{mo}$ & no \\
\hline & \multirow[t]{2}{*}{9} & \multirow[t]{2}{*}{$\begin{array}{l}\text { SL1+S } \\
\text { L3 }\end{array}$} & \multirow[t]{2}{*}{$\begin{array}{l}10-11-20 \\
11\end{array}$} & \multirow[t]{2}{*}{-} & \multirow[t]{2}{*}{-} & \multirow[t]{2}{*}{-} & \multirow[t]{2}{*}{$7 / 20 / 2012$} & \multirow[t]{2}{*}{4} & - & Sep-11 & $\begin{array}{l}\text { Hypoga } \\
\text { mma }\end{array}$ & $12 \mathrm{mo}$ & no \\
\hline & & & & & & & & & & & $\begin{array}{l}\text { globuline } \\
\text { mia }\end{array}$ & & \\
\hline & 10 & SL2 & $\begin{array}{l}11 / 29 / 20 \\
13\end{array}$ & - & - & - & $\begin{array}{l}12 / 29 / 201 \\
3\end{array}$ & 2 & - & Sep-13 & CID & $5 \mathrm{mo}$ & no \\
\hline & 11 & SL2 & $\begin{array}{l}11-04-20 \\
14\end{array}$ & - & - & - & & 1 & - & NA & $\begin{array}{l}\text { Suspecte } \\
\text { d PID }\end{array}$ & - & no \\
\hline
\end{tabular}


Citation: El-Sayed ZA, Mach O, Hossny EM, Galal NM, El-Sawy I, et al. (2016) Poliovirus Excretion among Persons with Primary Immune Deficiency Disorders: Summary of Data from Enhanced Poliovirus Surveillance in Egypt, 2011-2014. J Vaccines Vaccin 7: 331. doi: $10.4172 / 2157-7560.1000331$

Page 4 of 6

\begin{tabular}{|l|l|l|l|l|l|l|l|l|l|l|l|l|l|}
\hline & 12 & SL3 & $\begin{array}{l}10 / 21 / 20 \\
12\end{array}$ & & SL3 & & - & 2 & - & Jul-12 & CID & 4 mo & no \\
\cline { 2 - 10 } & 13 & SL3 & $\begin{array}{l}11-03-20 \\
14\end{array}$ & - & - & - & - & 1 & - & Oct-14 & $\begin{array}{l}\text { Other } \\
\text { PID }\end{array}$ & 8 mo & no \\
\hline
\end{tabular}

Table 2: Line list of poliovirus excretors among the primary immunodeficient children.

Among the patients with confirmed PID diagnoses who excreted iVDPVs, 5/6 (83\%) were diagnosed with severe combined immunodeficiency (SCID) of whom 4 passed away; 1/6 (17\%) was diagnosed with agammaglobulinemia (surviving); both of the surviving children were maintained on intravenous immunoglobulins (IVIG). One iVDPV excretor with SCID had normal QIG values at diagnosis yet his B cell count was repeatedly zero.

The duration of iVDPV excretion ranged from 2 months to 20 monthsbut only one person excreted iVDPV for more than 6 months; since December 2014, there have been no PID patients who excreted iVDPVs. Further, no secondary transmission of iVDPVs was reported.

Acute flaccid paralysis (AFP) was detected in $3 / 6(50 \%)$ of those excreting iVDPVs. All iVDPV excretors had history of receiving multiple doses of OPV. AFP was detected within a median of one month following last OPV dose.
Sequencing of iVDPVs detected divergence from Sabin polioviruses to be between 10 and 48 nucleotide substitutions in the VP1 region. Multiple samples were collected from several patients. There was one patient (patient 5 on Table 2) who had evolution of VDPV in multiple stool samples, and Figure 1 demonstrates the evolution of the poliovirus mutations over the 8 collections of stool samples (each stool collection is comprised of 2 samples). The screening of the first polio isolates indicated that the virus isolates were Sabin-Like (SL). Following the WHO algorithm, these isolates were not referred for sequencing. The second collection of stools more than one year later yielded virus isolate containing 38 nucleotide substitutions in VP1. From July 2012 to November 2012, the number of nucleotide substitutions increased to a maximum of 48 .

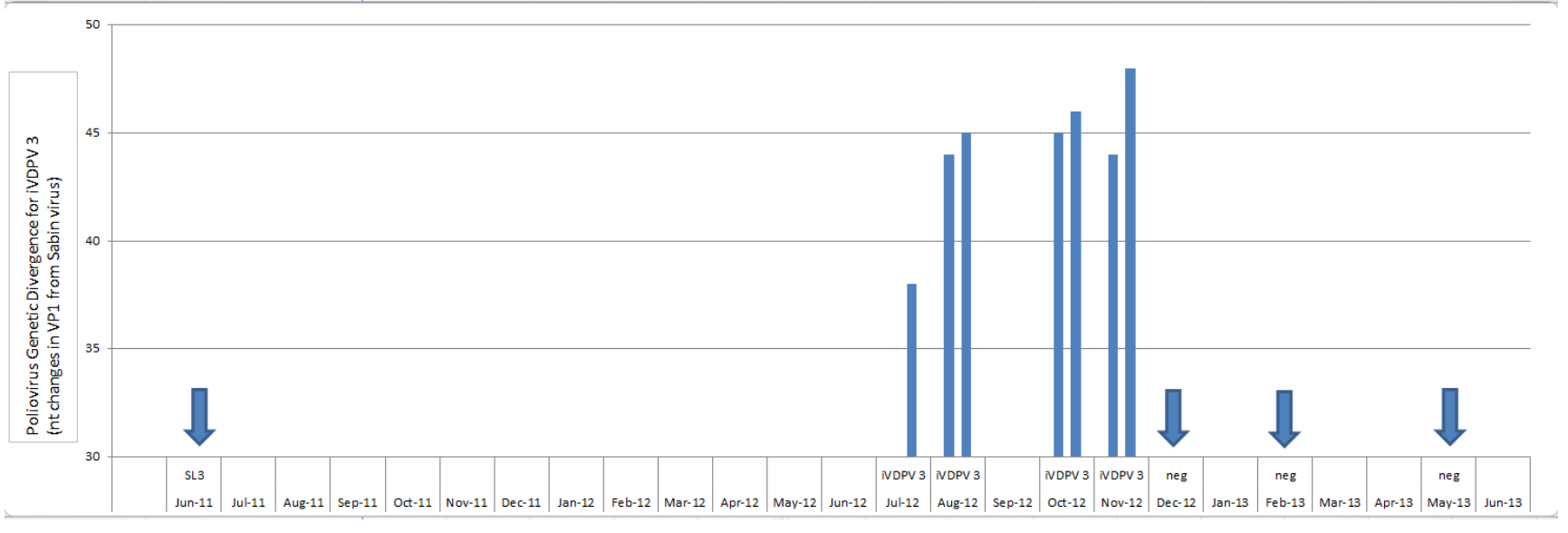

Figure 1: Divergence in VP1 sequence of poliovirus in Patient 5 (y axis: number of nucleotide changes in the VP1 sequence, arrows show dates of stool collection with SL3 or negative result), iVDPV: vaccine derived poliovirus in immunodeficient individual; SL: Sabin-like poliovirus.

\section{Discussion}

This is the first population-based surveillance study of PIDs with or without paralytic manifestations. Our study covered a population of $>50$ million, and focused on stimulation of identification (based on the ten Jeffrey Modell Foundation warning signs), reporting, and followup investigations in tertiary referral centers.

Our study in Egypt demonstrates that it is possible to establish a system to detect PID patients and test their stools for polioviruses in a low-middle income country. Prevalence of iVDPV excretion was relatively low and similar to previous observations [22,26,27]. The duration of excretion was generally short, with only with one patient excreting for more than 6 months. The short duration of excretion was influenced by early death due to severe infections unrelated to poliovirus in $4 / 6$ excretors. We observed clearance of iVDPV excretion in the 2 surviving children who were maintained on replacement therapy (IVIG). Current evidence regarding the effect of IVIG therapy on clearing persistent poliovirus infection is inconclusive $[8,28]$.

Patients' referral to pediatric immunology units and their follow-up was a consistent challenge, due to logistical and cultural barriers. Accordingly, the number of recruited cases might not represent the true frequency of PID in the general population and hence it may become necessary to establish a national registry to generate a more accurate estimate of PID prevalence for the purpose of identifying poliovirus excretors.

A study limitation was that surveillance was conducted on the pediatric age group only; hence, all detected PID patients were below 18 years of age with the more severe forms of PID. PIDs are usually recognized during infancy and early childhood, but some types of PID, 
such as CVID may be diagnosed later in life, commonly during the second decade of life or even later [29,30]. An additional limitation of this study was that there is incomplete data from several of the PID patients, due to loss to follow-up.

It is estimated that approximately 12 nucleotide mutations are expected to occur in one year in the VP1 genome of poliovirus [31]. Our finding demonstrated that iVDPV excretion was likely undetected for a prolonged period of time because we found patients excreting highly divergent iVDPVs. One complication in detecting and sequencing VDPVs from immunodeficient individuals is the presence of multiple virus lineages, which are closely genetically linked and are evolving over time. The mixed virus lineages can result in sequences with mixed base positions, which can be hard to resolve into distinct sequences [9]. This might have contributed to the classification of the first virus isolates as Sabin-Like, with no need for sequencing. Mixed virus lineages can also complicate the assignment of numbers of nucleotide substitutions, since more than one nucleotide is present and can lead to different consensus base calls. Limited amino acid substitutions in the neutralizing antigenic sites were observed (data not shown). The last dose of OPV for this patient (Table 2) in February 2011 is not likely to be the dose that initiated the emergence of VDPV because of the extensive number of nucleotide substitutions; 38 substitutions is about 3 fold more than would be predicted for 13 months using the poliovirus molecular clock [32].

Despite the low probability of iVDPV being transmitted to the general community and causing cVDPV outbreaks, it is imperative to continue with surveillance efforts to identify all VDPV excretors: the existence of VDPVs potentially circulating in communities may threaten poliovirus eradication $[8,33]$. OPV will be globally withdrawn from use; in April 2016, the trivalent OPV was replaced by bivalent OPV containing Sabin poliovirus serotypes 1 and 3.

Wild poliovirus serotype 2 has been eradicated, with the last case reported in 1999; after the switch from trivalent OPV to bivalent OPV, the iVDPV chronic excretors will remain the only potential source of poliovirus serotype 2 . Our ability to detect these individuals, and potentially treat them with antivirals, will be of high importance in the immediate post-eradication era.

Efforts to integrate AFP and iVDPV surveillance in non-paralyzed PID patients should continue in Egypt, as well as in other countries using OPV. Expansion of population-based surveillance efforts are being actively discussed, and should be considered by the Global Polio Eradication Initiative to identify PID patients with poliovirus infection, make therapeutic interventions available to clear the infection, and thus, to remove the threat of paralysis caused by poliovirus from these patients, but also to ultimately secure complete poliovirus eradication.

\section{References}

1. Sutter RW KO, Cochi SL (2013) Aylward BA Poliovirus Vaccine - live. Vaccines, 6th edition. Philadephia, PA: Elsevier, Inc. pp: 598-645

2. Terry L (1962) The association of cases of poliomyelitis with the use of type 3 oral poliomyelitis vaccines. Washington, DC: US Department of Health, Education, and Welfare.

3. Kew O, Morris-Glasgow V, Landaverde M, Burns C, Shaw J, et al. (2002) Outbreak of poliomyelitis in Hispaniola associated with circulating type 1 vaccine-derived poliovirus. Science 296:356-359.

4. Kew OM, Sutter RW, de Gourville EM, Dowdle WR, Pallansch MA (2005) Vaccine-derived polioviruses and the endgame strategy for global polio eradication. Annu Rev Microbiol 59: 587-635.
5. Notarangelo L, Casanova JL, Conley ME, Chapel H, Fischer A, et al. (2006) Primary immunodeficiency diseases: An update from the International Union of Immunological Societies Primary Immunodeficiency Diseases Classification Committee Meeting in Budapest, 2005. J Allergy Clin Immunol 117: 883-96.

6. Al-Herz W, Bousfiha A, Casanova JL, Chatila T, Conley ME, et al. (2014) Primary immunodeficiency diseases: an update on the classification from the international union of immunological societies expert committee for primary immunodeficiency. Front Immunol 5: 162.

7. Sutter R, Prevots D. (1994) Vaccine-associated paralytic poliomyelitis among immunologically abnormal persons. Infect Medicine 11: 426, 9-30, 35-38.

8. Kew OM, Sutter RW, Nottay BK, McDonough MJ, Prevots DR, et al. (1998) Prolonged replication of a type 1 vaccine-derived poliovirus in an immunodeficient patient. J Clin Microbiol 36: 2893-2899.

9. Yang CF, Chen HY, Jorba J, Sun HC, Yang SJ, et al. (2005) Intratypic Recombination among Lineages of Type 1 Vaccine-Derived Poliovirus Emerging during Chronic Infection of an Immunodeficient Patient. J Virol 79: 12623-12634.

10. Nathanson N, Kew OM (2010) From emergence to eradication: the epidemiology of poliomyelitis deconstructed. Am J Epidemiol 172: 1213-1229.

11. http://www.polioeradication.org/Dataandmonitoring/Poliothisweek/ Wildpolioviruslist.aspx. Accessed 07/06/2016.

12. Jenkins HE, Aylward RB, Gasasira A, Donnelly CA, Mwanza M, et al. (2010) Implications of a circulating vaccine-derived poliovirus in Nigeria. N Engl J Med 362: 2360-2369.

13. Wassilak S, Pate MA, Wannemuehler K, Jenks J, Burns C, et al. (2011) Outbreak of type 2 vaccine-derived poliovirus in Nigeria: emergence and widespread circulation in an underimmunized population. J Infect Dis 203: 898-909.

14. Burns CC, Shaw J, Jorba J, Bukbukc D, Adu F, et al. (2013) Multiple independent emergences of type 2 vaccine-derived polioviruses during a large outbreak in northern Nigeria. J Virol 87: 4907-4922.

15. Centers for Disease C, Prevention (2005) Poliovirus infections in four unvaccinated children--Minnesota, August-October 2005. MMWR Morb Mortal Wkly Rep 54: 1053-1055.

16. Alexander JP, Ehresmann K, Seward J, Wax G, Harriman K, et al. (2009) Transmission of imported vaccine-derived poliovirus in an undervaccinated community in Minnesota. J Infect Dis 199: 391-397.

17. Dunn G, Klapsa D, Wilton T, Stone L, Minor PD, et al. (2015) TwentyEight Years of Poliovirus Replication in an Immunodeficient Individual: Impact on the Global Polio Eradication Initiative. PLoS Pathog 11: e1005114.

18. Rhoden E, Liu HM, Wang-Chern SW, Oberste MS (2013) Anti-poliovirus activity of protease inhibitor AG-7404, and assessment of in vitro activity in combination with antiviral capsid inhibitor compounds. Antiviral Res 98: 186-191.

19. Exploring the Role of Antiviral Drugs in the Eradication of Polio (2006) In: Academies NRCotN, ed. Washington DC, USA.

20. WHO (1998) Acute flaccid paralysis (AFP) surveillance : the surveillance strategy for poliomyelitis eradication. WHO, Geneva.

21. Shahmahmoodi S, Parvaneh N, Burns C, Asghar H, Mamishi S, et al. (2008) Isolation of a type 3 vaccine-derived poliovirus (VDPV) from an Iranian child with X-linked agammaglobulinemia. Virus Res 137: 168-172.

22. Li L, Ivanova O, Driss N, Recto M, Silva RD, et al. (2014) Poliovirus excretion among persons with primary immune deficiency disorders: summary of a seven-country study series. J Infect Dis 210 Suppl 1: S368-372.

23. Centers for Disease Control (2000) Developing and expanding contributions of the global laboratory network for poliomyelitis eradication, 1997-1999. MMWR Morb Mortal Wkly Rep 49: 156-160.

24. http://www.cdc.gov/vaccines/pubs/surv-manual/chpt12-polio.html. Accessed 05/09/2016. 
Citation: El-Sayed ZA, Mach O, Hossny EM, Galal NM, El-Sawy I, et al. (2016) Poliovirus Excretion among Persons with Primary Immune Deficiency Disorders: Summary of Data from Enhanced Poliovirus Surveillance in Egypt, 2011-2014. J Vaccines Vaccin 7: 331. doi: $10.4172 / 2157-7560.1000331$

Page 6 of 6

25. Subbarayan A, Colarusso G, Hughes SM, Gennery AR, Slatter M, et al. (2011) Clinical features that identify children with primary immunodeficiency diseases. Pediatrics 127: 810-816.

26. Sazzad HM, Rainey JJ, Mach O, Roland S, Serguei D, et al. (2012) The feasibility of identifying children with primary immunodeficiency disorders: preparation for the polio post-eradication era in Bangladesh. Vaccine 30: 5396-5400.

27. Sazzad HM, Rainey JJ, Kahn AL, Mach O, Liyanage JBL, et al. (2014) Screening for Long-term Poliovirus Excretion Among Children With Primary Immunodeficiency Disorders: Preparation for the Polio Posteradication Era in Bangladesh. J Infect Dis 210 Suppl 1: S373-379.

28. Shahmahmoodi S, Mamishi S, Aghamohammadi A, Aghazadeh N, Tabatabaie H, et al. (2014) Vaccine-associated paralytic poliomyelitis in immunodeficient children, Iran, 1995-2008. Emerg Infect Dis 16:1133-1136.
29. Cunningham-Rundles C, Bodian C (1999) Common variable immunodeficiency: clinical and immunological features of 248 patients. Clin Immunol 92: 34-48.

30. Llobet MP, Soler-Palacin P, Detkova D, Hernandez M, Caragol I, et al. (2009) Common variable immunodeficiency: 20-yr experience at a single centre. Pediatr Allergy Immunol 20: 113-118.

31. Famulare M, Chang S, Iber J, Zhaob K, Adeniji JA, et al. (2015) Sabin vaccine reversion in the field: a comprehensive analysis of Sabin-like poliovirus isolates in Nigeria. J Virol.

32. Jorba J, Campagnoli R, De L, Kew O (2008) Calibration of multiple poliovirus molecular clocks covering an extended evolutionary range. J Virol 82: 4429-4440.

33. DeVries AS, Harper J, Murray A, Lexau C, Bahta L, et al. (2011) Vaccinederived poliomyelitis 12 years after infection in Minnesota. N Engl J Med 364: 2316-2323. 